\title{
The effects of intra- and post-operative anaesthesia and analgesia choice on outcome after gastric cancer resection: a retrospective study
}

\author{
Yu Wang ${ }^{1}$, Liping Wang ${ }^{1}$, Hong Chen ${ }^{1}$, Yang Xu${ }^{1}, X$ Xiaoyu Zheng ${ }^{1}$ and Guonian Wang ${ }^{1}$ \\ ${ }^{1}$ Department of Anaesthesiology, Cancer Hospital of Harbin Medical University, Harbin, China \\ Correspondence to: Guonian Wang, email: wangguonian609cn@aliyun.com \\ Keywords: anaesthesia, epidural and or general anaesthesia, patient-controlled analgesia, gastric cancer, overall survival \\ Received: February 13, $2017 \quad$ Accepted: March 01, 2017 \\ Published: March 30, 2017 \\ Copyright: Wang et al. This is an open-access article distributed under the terms of the Creative Commons Attribution License 3.0 (CC BY \\ 3.0), which permits unrestricted use, distribution, and reproduction in any medium, provided the original author and source are credited.
}

\section{ABSTRACT}

Background: Epidural use can provide a better short-term outcome and protect patients from the postoperative development of tumour recurrence and metastases. In this study, we sought to assess the effects of intra- and postoperative anaesthesia and analgesia choice on outcome after gastric cancer resection, searched for evidence of interaction between intra-and postoperative epidural use and outcomes of gastric cancer patients.

Methods: Four thousand two hundred and eighteen cases of gastric cancer were identified from the Records of Hospital Patients. Patients who received only general anesthesia (GA group) or epidural anesthesia combined with general anesthesia (EGA group), were administered patient-controlled intravenous or epidural analgesia for 72-120 hours postoperatively. Flatus time, length of stay in hospital, incidence of nausea and vomiting, and visual analogue scale (VAS ) scores were collected for evaluating the short-outcome of the patients. A Kaplan-Meier log-rank test was used for a univariable analysis, and Cox proportional hazards regressions were used for a multivariable analysis of the survival time in both groups.

Results: The VAS scores and incidence of nausea and vomiting in the EGA group were lower than the GA group. There was a significant association between intra-and postoperative epidural use and improved survival.

Conclusions: These results indicated that epidural anaesthesia combined with general anaesthesia and patient-controlled epidural analgesia may be associated with the improved overall survival in gastric cancer patients who underwent resection.

\section{INTRODUCTION}

Gastric cancer is one of the most common malignant tumours of the digestive tract in China, and surgery remains the first-line treatment for gastric cancer patients. $[1,2]$ Even if optimal surgical techniques are used, tumour surgeries may release tumour cells into the lymphatic and vascular systems. Moreover, a large fraction of patients already harbour remote foci of tumour cells at the time of surgery; thus undetectable micro-metastases may already exist even in cases involving apparently localized disease. [3-5] Whether minimal residual disease [6] or released tumour cells result in clinically apparent disease depends largely on the balance between immune activity and the ability of tumour cells to invade, proliferate, and promote angiogenesis. [7] Surgery-stimulated immunosuppression,such as the decreased activity of natural killer (NK) cells and lymphocytes, may induce growth and metastasis of residual cancer cells, thereby leading to a worse prognosis. [8] The other clinical events, such as opioid analgesia acute pain, general aneasthetics, and transfusion are also recognized as immunosuppressive, and as a result, tumour recurrence and metastases may occur frequently. [9-14] 
Epidural use has been shown to be associated with better analgesic effect, reducing flatus time, and length of hospital stay $[15,16]$, it can also decrease intra- and postoperative neuroendocrine stress responses, reduce opioid exposure that lead to immunosuppression, and relieve pain induced by surgery. $[17,18]$ These results lead to the hypothesis that epidural use may provide survival advantages in patients with several kinds of cancers. Recently, regional anaesthetic techniques have been demonstrated to be associated with better overall survival of several types of cancer, including breast cancer, hepatocellular carcinoma ,colorectal cancer. [19-22] Although widely believed to improve patient outcomes, results for survival after gastric cancer have been rarely reported. [23, 24] In this study, we sought to assess the interaction between intra-postoperative epidural analgesia and short/ long-term outcomes of gastric cancer.

\section{MATERIALS AND METHODS}

\section{Patient identification and exclusion}

After the study procedures were approved by the Ethics Committee of The Cancer Hospital of Harbin Medical University, 4218 gastric cancer cases were identified from the records of patients and patients admitted to the hospital for gastric cancer resection between 2008 and 2012 (Figure 1). Patients with metastasis, emergency operations and laparoscopic procedures were excluded. Patients who experienced anaesthesia and analgesia consisting with the following standard, and postoperative pathologies with gastric cancer were included. Medical records for all of the included patients were obtained, and the data were extracted by researchers who were not involved in the study or data analysis.

\section{Anaesthesia technique and grouping method}

Between 2008 and 2012, the local departmental policy was to offer either epidural anaesthesia in combination with general anaesthesia or general anaesthesia alone. Patients who received only general anaesthesia (GA group) underwent anaesthesia induced with midazolam $0.05-0.15 \mathrm{mg} / \mathrm{kg}, 0.5 \mu \mathrm{g} / \mathrm{kg}$ fentanyl and $1-2.5 \mathrm{mg} / \mathrm{kg}$ propofol. Propofol/sevoflurane and remifentanil/fentanyl were administered to maintain adequate anaesthesia depth during surgery. Patients received patient-controlled intravenous analgesia (PCIA) with $3 \mu \mathrm{g} / \mathrm{ml}$ fentanyl or $0.5 \mu \mathrm{g} / \mathrm{ml}$ sufentanil for 72 120 hours postoperatively. For patients who were given epidural anaesthesia (EGA group), a standard technique was used to insert a catheter into the epidural space of T8-T9 before induction of anaesthesia. Each of these patients was given a $3 \mathrm{ml}$ bolus of $1.33 \%$ lidocaine before induction of general anaesthesia. An infusion of $0.5 \%$ levobupivacaine or ropivacaine was administered to maintain an adequate anaesthetic concentration during surgery. In addition, patients received patient-controlled epidural analgesia ( PCEA) with $0.125 \%$ levobupivacaine combined with $2 \mu \mathrm{g} / \mathrm{ml}$ fentanyl or $0.2 \%$ ropivacaine combined with $2 \mu \mathrm{g} / \mathrm{ml}$ fentanyl were continued for 72 120 hours postoperatively.

\section{Indicator and data}

The statuses of patients up to March 31, 2015 were determined from medical records, and causes of death were recorded. Patients who died due to causes other than gastric cancer were censored. We obtained the following information: demographic data; cancer stage; American Society of Anaesthesiologists (ASA) grade; duration of surgery; axillary temperature after surgery; degree of differentiation; transfusion, preoperative or postoperative adjuvant chemotherapy, and/or radiation therapy; flatus time; length of stay; days of analgesia; visual analogue scale (VAS) scores were received. Cancer stage was assessed based on the $7^{\text {th }}$ edition of American Joint Committee on Cancer (AJCC) Cancer Staging Manual. The degrees of differentiation included well differentiated, other/unknown differentiated, moderate differentiated, and poorly differentiated. Survival time was measured from the date of gastrectomy to death or to the last followed-up before March 31, 2015.

\section{Statistical approach}

We recorded study data in an Excel spread sheet that was then imported into SAS software for analysis (version9.13, SAS Institute Inc, Cary, NC). The GA and EGA groups were compared with respect to all available potential confounders using Pearson Wilcoxon rank sum test, the chi-squared test, and Fisher's exact probability test, as appropriate. The survival time for the two groups was assessed using Kaplan-Meier log-rank test for the univariable analysis, and Cox proportional hazards regression for the multivariable analysis. Factors considered and retained in the multivariable models include age, cancer stage, degree of differentiation, duration of surgery, blood loss, transfusion and history of chemotherapy and radiotherapy. Associations with $P<$ 0.05 were deemed statistically significant.

\section{RESULTS}

\section{Patient characteristics}

Using the inclusion and exclusion criteria described above, we identified a cohort of 4218 patients (Figure 
Table 1: Baseline and surgical characteristics

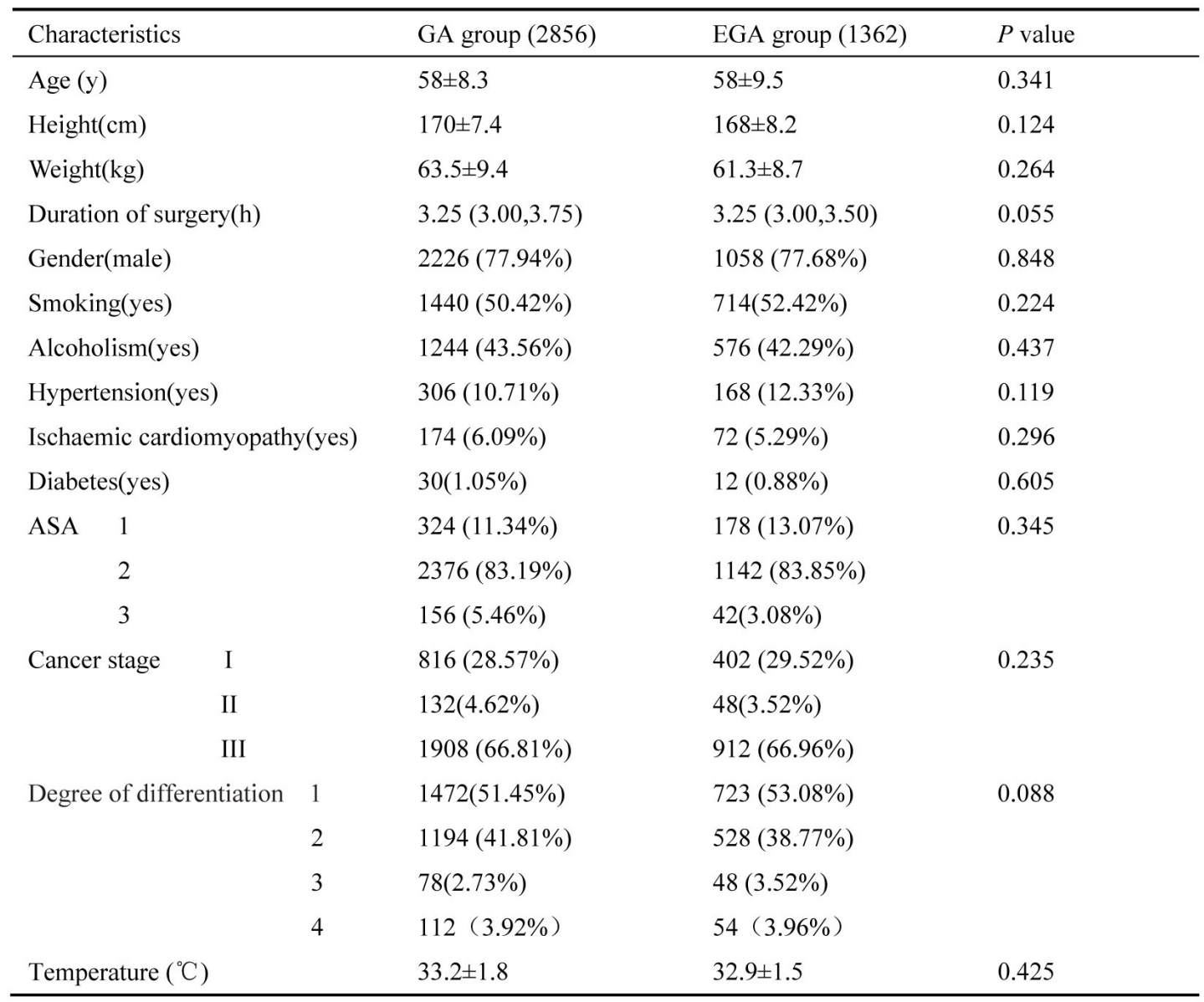

Abbreviations: EGA, epidural anaesthesia combined with general anaesthesia group; GA, general anaesthesia group; ASA, American Society of Anaesthesiologists.

Degrees of differentiation: Degree1, poorly differentiated; Degree2, moderately differentiated; Degree3, well differentiated; Degree 4, other/unknown differentiated.

Cancer stages: Stage I-T1, N0, M0/T2, N0, M0/T1, N1, M0; Stage II-T3, N0, M0/T4a, N1, M0/T3, N1, M0/T2, N2, M0/T1, N3, M0; Stage III-T2, N3, M0/T3, N2, M0/T3, N3, M0/T4a, N2, M0/T4a, N3, M0/any T4b, any N, M0; Stage IV, any T, any $\mathrm{N}, \mathrm{M} 1$.

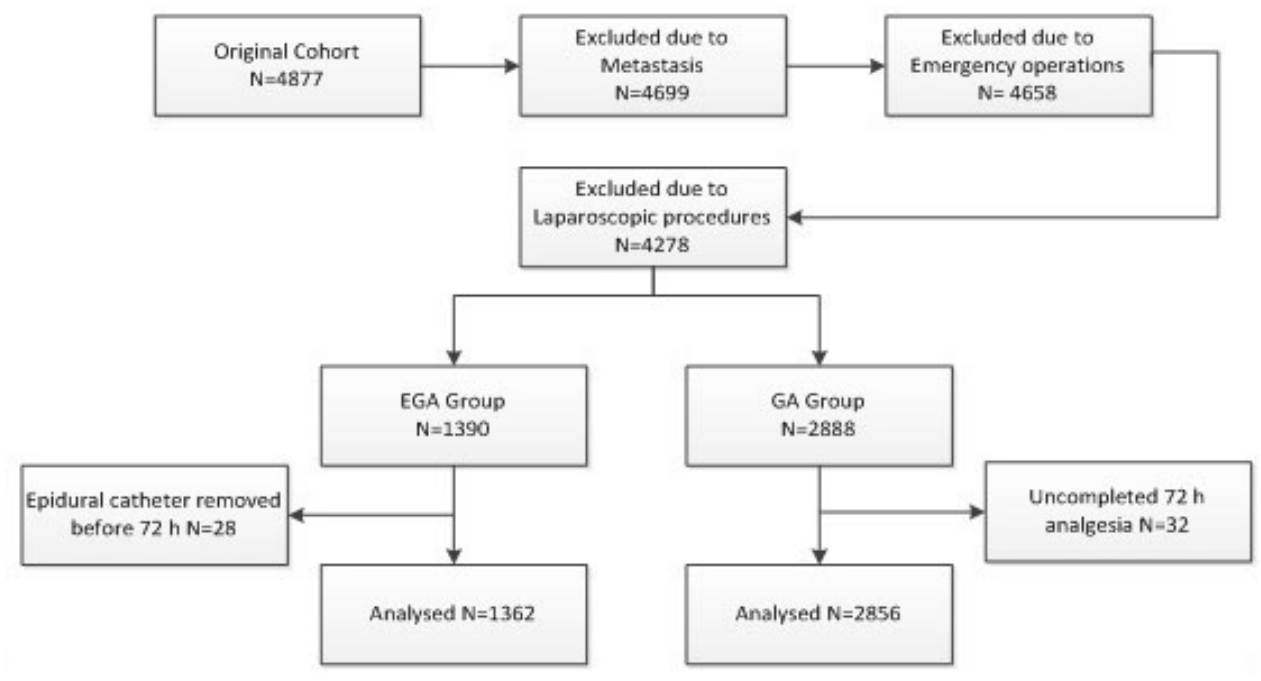

Figure 1: Patient identification and exclusion. 
Table 2: Short-term outcomes according to type of anaesthesia and analgesia

\begin{tabular}{|l|c|c|c|}
\hline \multicolumn{1}{|c|}{ Characteristics } & GA group (2856) & EGA group (1362) & P value \\
\hline Flatus time (days) & $4(3,5)$ & $4(3,5)$ & 0.427 \\
\hline Length of stay (days) & $19(17,22)$ & $18(17,21)$ & 0.123 \\
\hline Nausea and vomiting & $505(17.68 \%)$ & $228(16.74 \%)$ & $<0.05^{*}$ \\
\hline Days of analgesia(days) & $4(3,5)$ & $4(3,5)$ & 0.385 \\
\hline VAS scores & $3(2,5)$ & $2(1,4) *$ & \\
POD 1 & $2(1,4)$ & $1(0,3) *$ & $<0.001^{*}$ \\
POD 2 & $1(0,3)$ & $1(0,2) *$ & $<0.001^{*}$ \\
POD 3 & & & $<0.001^{*}$ \\
\hline
\end{tabular}

Abbreviations: VAS=Visual analogue scale (VAS) scores, POD=Postoperative day

Table 3: Univariate associations with survival

\begin{tabular}{|l|c|c}
\hline \multicolumn{1}{|c|}{ Factor } & $\boldsymbol{P}$ value & H R(95\%CI) \\
\hline Blood transfusion (yes vs. no) & $<0.0001^{*}$ & $0.61(0.49-0.78)$ \\
\hline Cancer stage (higher vs. lower) & $<0.0001^{*}$ & $1.41(1.29-1.45)$ \\
\hline Degree of differentiation (higher vs. lower) & $<0.0001^{*}$ & $0.67(0.61-0.74)$ \\
\hline Chemotherapy or radiation therapy (yes vs. no) & 0.486 & $0.97(0.87-1.07)$ \\
\hline Epidural use (EGA vs. GA) & $<0.0001^{*}$ & $0.65(0.58-0.73)$ \\
\hline Age $(\geq 65 y$ vs. $<65 y)$ & 0.439 & $1.05(0.93-1.18)$ \\
\hline
\end{tabular}

Table 4: Multivariate associations with survival: Cox multivariate Model 1, statistical effects only

\begin{tabular}{lll}
\hline \multicolumn{1}{c}{ Factor } & P value & HR(95\%CI) \\
\hline Blood transfusion (yes vs. no) & $<0.0012^{*}$ & $0.68(0.53-0.86)$ \\
Cancer stage (higher vs. lower) & $<0.0001^{*}$ & $1.35(1.28-1.43)$ \\
Degree of differentiation (higher vs. lower) & $<0.0001^{*}$ & $0.69(0.62-0.76)$ \\
Epidural use (EGA vs. GA) & $<0.0001^{*}$ & $0.70(0.63-0.77)$ \\
\hline
\end{tabular}

1), $67.7 \%$ of whom $(n=2856)$ were in the GA group, and $32.3 \%$ of whom $(n=1362)$ in the EGA group. The median follow-up times for the GA and EGA group were 42.5 months and 38.7 months. The groups exhibited no differences in age, height, weight, duration of surgery, gender, smoking history, alcoholism, hypertension history, ischaemic cardiomyopathy, diabetes, ASA grade or temperature after surgery. Moreover, no differences in cancer stage or degree of differentiation were observed between the two groups (Table 1).

\section{Association between epidural use and short- outcome}

Comparisons between the EGA and GA groups with respect to flatus time, length of hospital stay, incidence of nausea and vomiting, days of analgesia, and VAS scores are presented in Table 2. The EGA group had lower VAS scores $(P<0.01)$ and incidence of nausea and vomiting $(P<0.05)$ in the postoperative three days. Perioperative epidural use showed no associations with other short-term outcome variables, such as flatus time, days of analgesia and length of stay.

\section{Association between epidural use and long-term overall survival}

The mean survival times in the GA and EGA groups were 35.1 months and 40.2 months, respectively. Perioperative epidural use was associated with overall survival ( $P<0.0001$, long-rank test), with an estimated hazard ratio (HR) of 0.65 (95\% confidence interval [CI], $0.58-0.73$ ) in the univariable analysis (Table 3).Cancer stage $(\mathrm{HR}=1.41,95 \% \mathrm{CI} 1.29-1.45, P<0.0001)$ and degree of differentiation ( $\mathrm{HR}=0.67,95 \%$ CI $0.61-0.74$, $P<0.0001)$ were also associated with overall survival. In the multivariable Cox model that considered only the statistical effect of epidural use (Model 1, Table 4), cancer stage, degree of differentiation were associated with epidural use, which exhibited an adjusted estimated HR of 0.70 (95\% CI 0.63-0.77, $P<0.0001)$. Kaplan-Meier estimates of survival as a function of postoperative time for the two groups are provided in Figure 2. The resulting curves differed significantly ( $P<0.0001$, log-rank test).

\section{DISCUSSION}

The main findings of this retrospective study were as follows: Our results suggest an early and sustained 
beneficial effect of epidural use on tumour-related mortality after gastric cancer. Firstly, in our study, the EGA group had lower VAS scores on the postoperative three days. The results were consistent with that of a recently study, it found epidural use was associate with less number of additional doses of analgesics, and provided better analgesic effect, [25] both the two studies found no difference in length of hospital stay between the epidural and non-epidural use groups. In our study, there were no differences in flatus time between the two groups, while in the above mentioned study, the first time of flatus was earlier in the epidural group. The incidence of postoperative nausea and vomiting was higher in the GA group in our study, however, in the above mentioned study, there were no differences between the two groups , the reason may be that the prior study collected patients underwent laparoscopic distal gastrectomy, but we collected patients with all kinds of gastrectomy.

Secondly, there was a significant association between perioperative epidural use and improved survival. We identified associations between cancer stage, degree of differentiation and overall survival after gastric cancer resection, the findings were consistent with those of prior observational studies that evaluated other types of cancers, such as ovarian, [26] breast, [27]colorectal [28] and gastric cancer. $[23,24]$ We also found that epidural use can improve the long-term outcome of patients with gastric cancer, which was negative in one of the gastric cancer studies, [23] the author collected the patients who had been over 66 years old, but in our study, the patients' average age was 58 years old, and it has been found that epidural use was associated with reduced gastric cancer overall survival of younger patients, but not in older patients. [24] Our results were consistent with a study on gastro-esophageal cancer, it demonstrated that postoperative epidural analgesia can increase time to cancer recurrence and overall survival. [29] As mentioned previously, [23] the overall median survival durations were 28.1 months for the epidural group and 27.4 months for the non-epidural group, but in our study, the median survival durations for the EGA and GA groups were 40.2 and 35.1 months, respectively, that can also be explained by differences in patient populations, surgical technique, and time of admission.(our data provided greater age range and later admission time)

Tumour surgeries may release tumour cells into the lymphatic and vascular systems, whether released or harboured tumour cells result in clinically apparent disease depends largely on the balance between immune activity and the ability of tumor cells to invade, proliferate, and promote angiogenesis. Since immune surveillance is the first indicator for preventing cancer metastasis, immunesuppression may decrease the defensive barrier against tumour cells. [30] Clinical events that may lead to altered immune response after surgical trauma include tissue injury, pain, general anaesthesia, blood transfusion, and opioid drugs . [31-33] These clinical events stimulate activation of the hypothalamic-pituitaryadrenal (HPA) axis and the sympathetic nervous system (SNS) during the perioperative period. [34]The activation of multiple biological cascades leads to postoperative immunosuppression, which affects both humoral and cell-mediated responses. $[10,11]$ Then it lead to the suppression of NK cells and cytotoxic ( CTLs), in

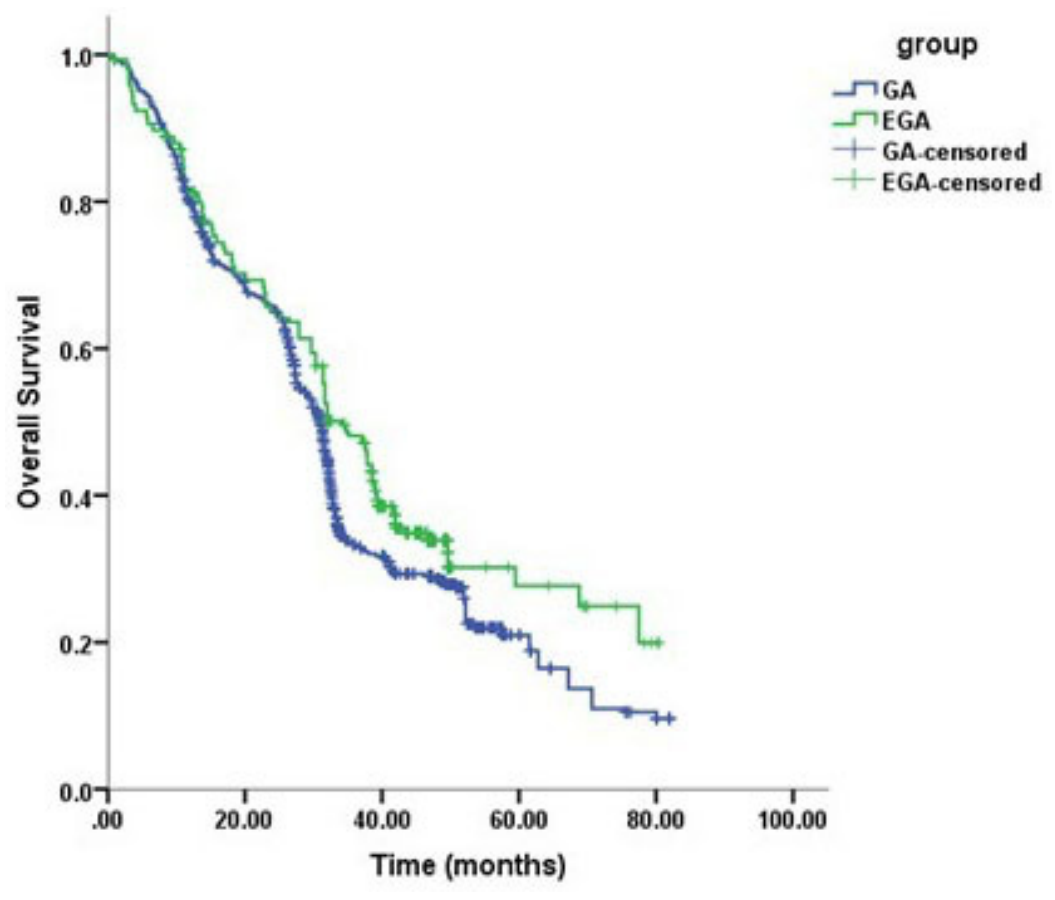

Figure 2: Kaplan-Meier survival curves for patients with and without epidural use (univariate $P<0.0001 *$ ). 
association with a decrease in interleukin-12 (IL-12), tumour necrosis factor- $\alpha$ (TNF- $\alpha$ ), and interferon- $\gamma$ (IFN- $\gamma$ ). [35] In our study, the EGA group had lower VAS scores on the postoperative three days, the immune function of patients in the EGA group may be less influenced, that may be the reason of better outcome in the EGA group.

The acute and chronic administration of opioids also inhibits components of cellar and humoral immune function from suppressing NKcell activity. [36-38]It has been proved that $\mu$-opioid receptor agonists transactivate pro-oncogenic vascular endothelial growth factors (VEGF) and epidermal growth factor (EGF) receptors resulting in enhanced tumour growth (reversed by opioid receptor antagonism). [39] Epidural anaesthesia can decrease intra- and postoperative neuro-endocrine stress responses, [40-42] reduce opioid exposure [29, 33, 43] that leads to immunosuppression, then it may improve the outcome of cancer patients. It is a pity that we couldn't collect the total volumes of opioid drugs or rescue analgesics, so the hypothesis of epidural use improved overall survival through less opioid exposure was not confirmed in our study. On the other hand, there were some studies suggest that epidural anaesthesia could not protect patients from immunosuppression in upper abdominal surgery, [44, 45] so the hypothesis that epidural use can improve overall survival of gastric cancer is still controversial, and the interaction between epidural use and outcomes of gastric cancer is influenced by several kinds of mechanisms.

We found an association between perioperative blood transfusion and an increased hazard for mortality which is consistent with the increasing recognized negative effects of transfusion. Kenneth et al [28] and Glance et al [46] found an association between blood transfusion and an increased risk of death, in gastric cancer and non cardiac surgery. This may because blood transfusion can induce suppressed immune functions. Alternative explanations are that the surgery on patients with comorbidities (anemia of chronic disease), or that surgery on patients requiring transfusion was more complex imposing greater inflammatory load. [29]

Our study had certain limitations. Firstly, the clinical data, such as detailed surgical techniques, special drugs administered, perioperative opioid use which induced biases, could not be collected. Secondly, we were unable to determine certain indices that reflected immune systemic functions, therefore, we should design prospective studies to clearly elucidate the mechanisms underlying our results, NK cell activity and markers of immunological function, such as cytokines and cortisol will be measured.

In conclusion, this study suggests that epidural anaesthesia combined with general anaesthesia and patient-controlled epidural analgesia may provide better analgesic effect and be associated with the improved overall survival in gastric cancer patients who underwent resection.

\section{Author contributions}

Y.W., L.W. and G.W. designed the study; H.C., Y.X. and X.Z. collected the data; Y.W. and H.C. analysed the data; Y.W. wrote the manuscript.

\section{CONFLICTS OF INTEREST}

The authors have no conflicts of interest to declare.

\section{FUNDING}

This study was funded by the foundation of the National Natural Science Foundation of China (Grant\#81571885) and the foundation of Heilongjiang Academy of Medical Sciences, Heilongjiang, China (Grant \#201612).

\section{REFERENCES}

1. Marrelli D, De Stefano A, de Manzoni G, Morgagni P, Di Leo A, Roviello F. Prediction of recurrence after radical surgery for gastric cancer: a scoring system obtained from a prospective multicenter study. Ann Surg. 2005; 241:24755.

2. Eschwège $P$, Dumas $F$, Blanchet $P$, Le Maire V, Benoit G, Jardin A, Lacour B, Loric S. Haematogenous dissemination of prostatic epithelial cells during radical prostatectomy. Lancet. 1995; 346:1528-30.

3. Denis MG, Lipart C, Leborgne J, LeHur PA, Galmiche JP, Denis M, Ruud E, Truchaud A, Lustenberger P. Detection of disseminated tumor cells in peripheral blood of colorectal cancer patients. Int J Cancer. 1997; 74:540-44.

4. Mansi JL, Gogas H, Bliss JM, Gazet JC, Berger U, Coombes RC. Outcome of primary-breast-cancer patients with micrometastases: a long-term follow-up study. Lancet. 1999; 354:197-202.

5. Holmgren L, O'Reilly MS, Folkman J. Dormancy of micrometastases: balanced proliferation and apoptosis in the presence of angiogenesis suppression. Nat Med. 1995; $1: 149-53$.

6. Snyder GL, Greenberg S. Effect of anaesthetic technique and other perioperative factors on cancer recurrence. Br J Anaesth. 2010; 105:106-15.

7. Kehlet H. Manipulation of the metabolic response in clinical practice. World J Surg. 2000; 24:690-95.

8. Forget P, Collet V, Lavand'homme P, De Kock M. Does analgesia and condition influence immunity after surgery? Effects of fentanyl, ketamine and clonidine on natural killer activity at different ages. Eur J Anaesthesiol. 2010; 27:23340.

9. Oka M, Hazama S, Suzuki M, Wang F, Shimoda K, Iizuka N, Wadamori K, Suzuki T, Attwood S. Depression of cytotoxicity of nonparenchymal cells in the liver after 
surgery. Surgery. 1994; 116:877-82.

10. Lennard TW, Shenton BK, Borzotta A, Donnelly PK, White M, Gerrie LM, Proud G, Taylor RM. The influence of surgical operations on components of the human immune system. Br J Surg. 1985; 72:771-76.

11. Page GG, Blakely WP, Ben-Eliyahu S. Evidence that postoperative pain is a mediator of the tumor-promoting effects of surgery in rats. Pain. 2001; 90:191-99.

12. Yeager MP, Colacchio TA, Yu CT, Hildebrandt L, Howell AL, Weiss J, Guyre PM. Morphine inhibits spontaneous and cytokine-enhanced natural killer cell cytotoxicity in volunteers. Anesthesiology. 1995; 83:500-08.

13. Yi W, Li D, Guo Y, Zhang Y, Huang B, Li X. Sevoflurane inhibits the migration and invasion of glioma cells by upregulating microRNA-637. Int J Mol Med. 2016; 38:1857-63.

14. Müller-Edenborn B, Frick R, Piegeler T, Schläpfer M, RothZ'graggen B, Schlicker A, Beck-Schimmer B. Volatile anaesthetics reduce neutrophil inflammatory response by interfering with CXC receptor-2 signalling. Br J Anaesth. 2015; 114:143-49.

15. Shi WZ, Miao YL, Yakoob MY, Cao JB, Zhang H, Jiang YG, Xu LH, Mi WD. Recovery of gastrointestinal function with thoracic epidural vs. systemic analgesia following gastrointestinal surgery. Acta Anaesthesiol Scand. 2014; 58:923-32.

16. Guay J, Nishimori M, Kopp S. Epidural local anaesthetics versus opioid-based analgesic regimens for postoperative gastrointestinal paralysis, vomiting and pain after abdominal surgery. Cochrane Database Syst Rev. 2016; 7:CD001893.

17. Chen WK, Miao CH. The effect of anesthetic technique on survival in human cancers: a meta-analysis of retrospective and prospective studies. PLoS One. 2013; 8:e56540.

18. Byrne K, Levins KJ, Buggy DJ. Can anesthetic-analgesic technique during primary cancer surgery affect recurrence or metastasis? Can J Anaesth. 2016; 63:184-92.

19. Cata JP, Chavez-MacGregor M, Valero V, Black W, Black DM, Goravanchi F, Ifeanyi IC, Hernandez M, RodriguezRestrepo A, Gottumukkala V. The Impact of Paravertebral Block Analgesia on Breast Cancer Survival After Surgery. Reg Anesth Pain Med. 2016; 41:696-703.

20. Lai R, Peng Z, Chen D, Wang X, Xing W, Zeng W, Chen M. The effects of anesthetic technique on cancer recurrence in percutaneous radiofrequency ablation of small hepatocellular carcinoma. Anesth Analg. 2012; 114:290 96.

21. Myles PS, Peyton P, Silbert B, Hunt J, Rigg JR, Sessler DI, ANZCA Trials Group Investigators. Perioperative epidural analgesia for major abdominal surgery for cancer and recurrence-free survival: randomised trial. BMJ. 2011; 342:d1491.

22. Wigmore TJ, Mohammed K, Jhanji S. Long-term Survival for Patients Undergoing Volatile versus IV Anesthesia for Cancer Surgery: A Retrospective Analysis. Anesthesiology.
2016; 124:69-79.

23. Cummings $\mathrm{KC}$ 3rd, Patel M, Htoo PT, Bakaki PM, Cummings LC, Koroukian S. A comparison of the effects of epidural analgesia versus traditional pain management on outcomes after gastric cancer resection: a population-based study. Reg Anesth Pain Med. 2014; 39:200-07.

24. Wang J, Guo W, Wu Q, Zhang R, Fang J. Impact of Combination Epidural and General Anesthesia on the LongTerm Survival of Gastric Cancer Patients: A Retrospective Study. Med Sci Monit. 2016; 22:2379-85.

25. Yanagimoto $\mathrm{Y}$, Takiguchi S, Miyazaki Y, Mikami J, Makino T, Takahashi T, Kurokawa Y, Yamasaki M, Miyata H, Nakajima K, Mori M, Doki Y. Comparison of pain management after laparoscopic distal gastrectomy with and without epidural analgesia. Surg Today. 2016; 46:229-34.

26. Lin L, Liu C, Tan H, Ouyang H, Zhang Y, Zeng W. Anaesthetic technique may affect prognosis for ovarian serous adenocarcinoma: a retrospective analysis. $\mathrm{Br} \mathrm{J}$ Anaesth. 2011; 106:814-22.

27. Exadaktylos AK, Buggy DJ, Moriarty DC, Mascha E, Sessler DI. Can anesthetic technique for primary breast cancer surgery affect recurrence or metastasis? Anesthesiology. 2006; 105:660-64.

28. Cummings $\mathrm{KC}$ 3rd, Xu F, Cummings LC, Cooper GS. A comparison of epidural analgesia and traditional pain management effects on survival and cancer recurrence after colectomy: a population-based study. Anesthesiology. 2012; 116:797-806.

29. Hiller JG, Hacking MB, Link EK, Wessels KL, Riedel BJ. Perioperative epidural analgesia reduces cancer recurrence after gastro-oesophageal surgery. Acta Anaesthesiol Scand. 2014; 58:281-90.

30. Melamed R, Rosenne E, Shakhar K, Schwartz Y, Abudarham N, Ben-Eliyahu S. Marginating pulmonary-NK activity and resistance to experimental tumor metastasis: suppression by surgery and the prophylactic use of a beta-adrenergic antagonist and a prostaglandin synthesis inhibitor. Brain Behav Immun. 2005; 19:114-26.

31. Buckley A, McQuaid S, Johnson P, Buggy DJ, Hemmings HC. Effect of anaesthetic technique on the natural killer cell anti-tumour activity of serum from women undergoing breast cancer surgery: a pilot study. Br J Anaesth. 2014 (Suppl 1); 113:i56-62.

32. Sekandarzad MW, van Zundert AA, Lirk PB, Doornebal CW, Hollmann MW. Perioperative Anesthesia Care and Tumor Progression. Anesth Analg. 2016.

33. Bharati SJ, Chowdhury $\mathrm{T}$, Bergese SD, Ghosh S. Anesthetics impact on cancer recurrence: what do we know? J Cancer Res Ther. 2016; 12:464-68.

34. Kim R. Anesthetic technique and cancer recurrence in oncologic surgery: unraveling the puzzle. Cancer Metastasis Rev. 2016.

35. Greenfeld K, Avraham R, Benish M, Goldfarb Y, Rosenne E, Shapira Y, Rudich T, Ben-Eliyahu S. Immune 
suppression while awaiting surgery and following it: dissociations between plasma cytokine levels, their induced production, and NK cell cytotoxicity. Brain Behav Immun. 2007; 21:503-13.

36. Connolly C, Buggy DJ. Opioids and tumour metastasis: does the choice of the anesthetic-analgesic technique influence outcome after cancer surgery? Curr Opin Anaesthesiol. 2016; 29:468-74.

37. Liang X, Liu R, Chen C, Ji F, Li T. Opioid System Modulates the Immune Function: A Review. Transl Perioper Pain Med. 2016; 1:5-13.

38. Hou M, Zhou NB, Li H, Wang BS, Wang XQ, Wang XW, Wang KG, Xue FS. Morphine and ketamine inhibit immune function of gastric cancer patients by increasing percentage of CD4(+)CD25(+)Foxp3(+) regulatory T cells in vitro. J Surg Res. 2016; 203:306-12.

39. Fujioka N, Nguyen J, Chen C, Li Y, Pasrija T, Niehans G, Johnson KN, Gupta V, Kratzke RA, Gupta K. Morphineinduced epidermal growth factor pathway activation in nonsmall cell lung cancer. Anesth Analg. 2011; 113:1353-64.

40. Buggy DJ, Smith G. Epidural anaesthesia and analgesia: better outcome after major surgery? Growing evidence suggests so. BMJ. 1999; 319:530-31.

41. Shavit Y, Ben-Eliyahu S, Zeidel A, Beilin B. Effects of fentanyl on natural killer cell activity and on resistance to tumor metastasis in rats. Dose and timing study. Neuroimmunomodulation. 2004; 11:255-60.
42. Ben-David B. Anaesthesia in Cancer Surgery: Can it Affect Cancer Survival? Curr Clin Pharmacol. 2016; 11:4-20.

43. Gottschalk A, Ford JG, Regelin CC, You J, Mascha EJ, Sessler DI, Durieux ME, Nemergut EC. Association between epidural analgesia and cancer recurrence after colorectal cancer surgery. Anesthesiology. 2010; 113:2734.

44. Norman JG, Fink GW. The effects of epidural anesthesia on the neuroendocrine response to major surgical stress: a randomized prospective trial. Am Surg. 1997; 63:75-80.

45. Kawasaki T, Ogata M, Kawasaki C, Okamoto K, Sata T. Effects of epidural anaesthesia on surgical stress-induced immunosuppression during upper abdominal surgery. Br J Anaesth. 2007; 98:196-203.

46. Glance LG, Dick AW, Mukamel DB, Fleming FJ, Zollo RA, Wissler R, Salloum R, Meredith UW, Osler TM. Association between intraoperative blood transfusion and mortality and morbidity in patients undergoing noncardiac surgery. Anesthesiology. 2011; 114:283-92. 